\title{
THE DEGRADATION OF PHENOL IN WATER SOLUTION BY TiO PHOTOCATALYSIS IN A HELICAL REACTOR
}

\author{
N.A. LAOUFI* \\ D. TASSALIT \\ F. BENTAHAR
}

\author{
Université des Sciences et de la Technologie \\ Houari Boumediène \\ Faculté de Génie Mécanique et de Génie des Procédés \\ Département de Cryogénie et de Génie Chimique.Laboratoire \\ des Phénomènes de Transfert \\ Bp 32, El Alia, 16111 Bab Ezzouar, Algeria
}

Received: $24 / 12 / 07$

Accepted: 18/03/08 *to whom all correspondence should be addressed: Fax: 0021321672897; e-mail: nadialaoufi@yahoo.fr

\section{ABSTRACT}

Heterogeneous photocatalysis is an advanced oxidation process (AOP) which has been widely studied by numerous researchers in the world and is used to degrade or remove a wide range of pollutants in water and air.

The photocatalytic oxidation and mineralization of phenol in aqueous catalyst suspensions of titanium dioxide $\left(\mathrm{TiO}_{2}\right)$ Degussa P25 (80\% anatase, 20\% rutile) has been carried out in a helical reactor. The photodegradation was investigated using two kinds of high pressure mercury irradiation lamps one emitting at $254 \mathrm{~nm}$ (15 Watts) and the other emitting at $365 \mathrm{~nm}$ (400 Watts). The effects of the recirculation flow, source of withdrawal, initial phenol concentration, amount of catalyst, suspension $\mathrm{pH}$ and light intensity on photodegradation of phenol were investigated. These parameters were studied to find the optimal conditions for a complete and fast oxidation of this organic compound.

Kinetic experiments were performed at $32{ }^{\circ} \mathrm{C}$ over a range of phenol concentrations from 2.5 to $25 \mathrm{mg} \mathrm{l}^{-1}$, a range of $\mathrm{TiO}_{2}$ concentrations from 0.1 to $1 \mathrm{~g} \mathrm{I}^{1}$, a range of suspensions $\mathrm{pH}$ from 3 to 9 . The helical reactor was operated under a continuous flow-mode.

Results showed that photodegradation is an effective method for the removal of phenol from wastewaters. The efficiency of the process depends strongly on the experimental conditions. The amount of catalyst, UV irradiation time, $\mathrm{pH}$ and light intensity were important parameters in the degradation process. The rate constants for the different parameters $\left(\mathrm{TiO}_{2}\right.$, phenol concentration) were evaluated. Kinetic studies showed that titanium dioxide photocatalyst P25 was very active in phenol degradation; we observed that $99 \%$ of pollutant was degraded after 6 hours of UV irradiation; furthermore, we observed that phenol degradation was more effective under acidic conditions than alkaline. The kinetics were described by the LangmuirHinshelwood (L-H) kinetic model. An overall pseudo-first order kinetic constant has been calculated for phenol conversion and values obtained in acidic $\mathrm{pH}$ are higher than those calculated for basic $\mathrm{pH}$ media.

KEYWORDS: Degradation, AOP, Photocatalysis, Phenol, Catalyst, Kinetic equations, $\mathrm{TiO}_{2} / \mathrm{UV}$.

\section{INTRODUCTION}

Phenol and its derivatives are widely used in many petrochemical industries and petroleum refineries as well as chemical and pharmaceutical industries. As the toxicity of phenolic compounds is an important problem, their concentration unfortunately inhibits or even eliminates micro-organisms in biological wastewater treatment plant. Therefore, the presence of phenols strongly reduces the biological biodegradation of the other components. Several processes have been used to eliminate phenolic compounds, conventional destructive technologies including biological treatment and adsorption over activated carbon treatment processes are effective in water treatment but they only transfer the contaminants from one 
medium to another. Furthermore, they are slow processes and at higher concentrations of the organic contaminants, they present some difficulties during the operation (Pelizzetti et al., 1990). During the past decade, great interest has been focused on a promising technology based on the oxidation of the hazardous and refractory organic compounds, by the use of advanced oxidation processes (AOPs) (Tennakone et al., 1997; Azbar et al., 2004 and Mokrini et al., 1997). The AOPs are based on the generation of hydroxyl radicals $\left(\mathrm{HO}^{\circ}\right)$ which are the principal agents responsible for the oxidation of numerous aqueous organic contaminants (Legrini et al., 1993; Huang et al., 1993). This species is a powerful oxidant; however due to its high reactivity, it is unstable and must be continuously produced in situ by means of chemical or photochemical reactions. Among the different ways to generate the hydroxyl radicals are: ozone with ultraviolet light (Glaze et al., 1982; Mirat et al., 1997; Esplugas et al., 1994), hydrogen peroxide with ultraviolet light, and photocatalysis, which uses a semi-conductor in combination with UV radiation and molecular oxygen (Weir et al.,1993; and Brezova et al.,1991). Some of these processes like ozonation are more expensive than the use of a catalyst with UV irradiation.

As one of the AOPs, photocatalytic oxidation of a wide variety of organic contaminants by semi conductors has been investigated in more detail during the past decade ( Ollis et al., 1985). The use of titanium dioxide (Matthews, 1990) as a photocatalyst has been of great interest due to its efficiency nontoxicity, high activity, photochemical inertness and low cost. Degussa P25, which has both anatase and rutile forms, with the ratio of anatase to rutile equal to $4: 1$, is one of the best $\mathrm{TiO}_{2}$ photocatalysts and used frequently as a reference in photocatalysis (Hoffman et al.,1995; Hagfeldt et al.,1995; Fox et al., 1993). This photocatalyst is the most studied and is activated by ultraviolet (UV) light (wavelength < 400nm) due to its band gap of 3.2eV (Tang et al., 1994; Kayan et al., 1996).

Numerous methods have been used to effectively degrade phenol (Salinaro et al., 1999). These methods are based on Advanced Oxidation Processes including processes that use hydrogen peroxide and ferrous ions (Al-Hayek et al., 1990; Guélou et al., 2003 and Bremner et al., 2006) or use semi-conductors like titanium dioxide. The advantage of these processes is that they lead to the total mineralization of organic contaminants, whether they are simple or complex molecules. Nowadays, the most efficient procedure for the treatment of contaminated water is the heterogeneous photocatalysis; it consists of UV light irradiation of $\mathrm{TiO}_{2}$ catalyst suspensions in solutions containing the organic substrate to be degraded.

The purpose of this work was to study the effectiveness of a helical reactor, conceived in our laboratory, on the photodegradation of phenol. The experiments were conducted in aqueous suspensions of $\mathrm{TiO}_{2}$, varying different parameters such as the amount of catalyst, UV irradiation time, $\mathrm{pH}$ and light intensity. The model proposed by Langmuir-Hinshelwood (L-H) was employed to describe the kinetics of the photodecomposition reactions of phenol, and the optimal conditions have been determined.

\section{PRINCIPLE OF THE HETEROGENEOUS PHOTOCATALYSIS}

The heterogeneous photocatalysis, one of the Advanced Oxidation Processes, permits the total degradation (mineralization) of the most toxic organic molecules in aqueous solution in the presence of a catalyst. These processes are based on the generation of hydroxyl radicals $\mathrm{HO}^{\circ}$ (Okamoto et al., 1985; Serpone, 1996). This species is a powerful oxidant due to its high reactivity. It is unstable and must be continuously produced in situ by means of chemical or photochemical reactions (Andreozzi et al., 1999; Chiron et al., 2000; Galze et al., 1992; Safarzadeh -Amiri et al., 1996).

The heterogeneous photocatalysis is based on a semiconductor used as catalyst which is activated by UV light. The anatase form of Titanium dioxide is mainly used as the catalyst, because of its high activity. The photocatalytic process consists of the excitation of the titanium dioxide by a UV light wavelength of $\lambda \leq 400 \mathrm{~nm}$, electron-hole pairs $\left(\mathrm{e}_{\overline{c b}}^{-}, \mathrm{h}_{\mathrm{vb}}^{+}\right)$are generated (Figure 1), the hydroxyl radicals are generated by the hole which can degrade organic pollutants present in the wastewater. Oxygen, provided from the air (when the system 
is stirred), dissolved in the solution scavenges the electron generated, preventing the recombination of electrons and holes.

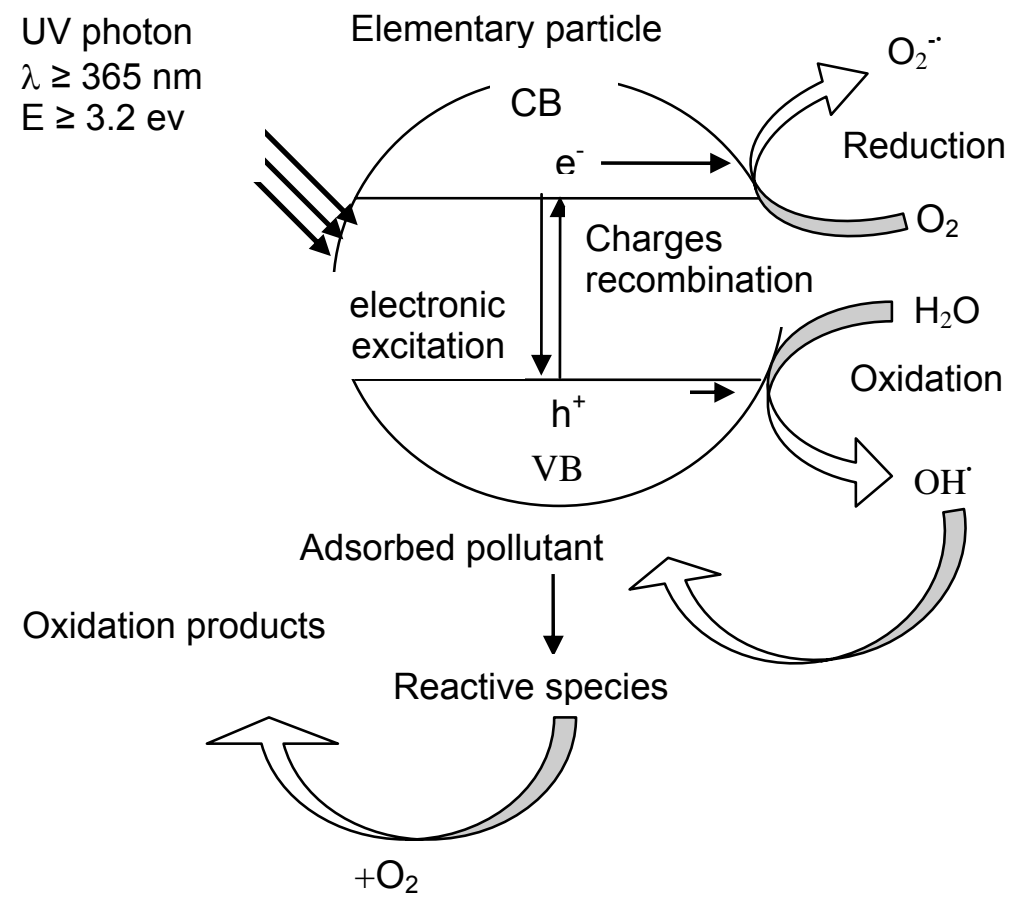

Figure 1. Mechanism diagram of photocatalytic degradation

UV illumination of $\mathrm{TiO}_{2}$ yields conduction band electrons and valence band holes (eq.i), which interact with surface adsorbed molecular oxygen to yield superoxide radical anions, $\mathrm{O}_{2}^{-\bullet}$ (eq.ii), and with water to produce the highly reactive $\mathrm{HO}^{\bullet}$ radicals ((eq.iii), respectively. The latter radical species are well known to oxidize a large number of organic substrates (eq.iv), (Horikoshi et al., 2001; Emeline et al., 2001).

$\mathrm{TiO}_{2}+\mathrm{hv} \rightarrow \mathrm{e}_{\mathrm{cb}}^{-}+\mathrm{h}_{\mathrm{vb}}^{+}$

$\mathrm{e}_{\mathrm{cb}}^{-}+\mathrm{O}_{2(\text { ads })} \rightarrow \mathrm{O}_{2}^{-\bullet}$

$\mathrm{h}_{\mathrm{vb}}^{+}+\mathrm{Ti}-\mathrm{OH}_{2} \rightarrow \mathrm{HO}_{\mathrm{ads}}^{\bullet}+\mathrm{H}^{+}$

$\mathrm{HO}_{\text {ads }}^{\bullet}+$ Substrate $\rightarrow$ Photooxidized $\cdot$ products

\section{MATERIALS AND METHODS}

\subsection{Reagents}

The chosen catalyst of titanium dioxide, mainly anatase $(80 \%$ anatase and $20 \%$ rutile, Degussa P 25) (Datye et al., 1995) with a particle size of $30 \mathrm{~nm}$ and a surface area of $50 \mathrm{~m}^{2}$ $\mathrm{g}^{-1}$ obtained by BET analysis was used without any pre-treatment; this catalyst is the best one which gives an optimal efficiency of catalysis, furthermore, good interparticle contacts are formed between anatase and rutile particles in water (Ohno et al., 2001). Phenol was obtained with purity $>99.9 \%$. All the chemicals that were used in the experiments were of laboratory reagent grad and used as received without further purification. The solutions were prepared with distilled water. The solution $\mathrm{pH}$ was adjusted by nitric acid $\left(\mathrm{HNO}_{3}\right)$ or potassium hydroxide $(\mathrm{KOH})$. 


\subsection{Photoreactor}

All experiments were performed in the experimental installation shown in Figure 2. The helical photoreactor of $500 \mathrm{ml}$ capacity was constructed in Pyrex. It is comprised of 23 spires with a 7 $\mathrm{mm}$ interior diameter and a length of $400 \mathrm{~mm}$. The source of irradiation is placed in the center of the reactor to assure the maximum energy exchange between the source of irradiation and reaction mixture that flows out continuously. The tubular compartment surrounding the lamp has an interior and outer diameter equal to 60 and $80 \mathrm{~mm}$, respectively, a length of $50 \mathrm{~cm}$ are used as a cooling system. A pump recirculates the mixture between the reactor and the reservoir as shown in Figure 1. The reservoir is conceived according to the norms of Holland and Chapman, (1966) it is a cylindrical container made of Pyrex, with a diameter of $23.6 \mathrm{~cm}$. It is equipped with four baffles made of Plexiglas fixed perpendicularly to the partition of the vat. The UV radiation sources are $15 \mathrm{~W}$ and $400 \mathrm{~W}$ low-pressure mercury vapor quartz lamps (Philips TL 05 and HPA, respectively). The lamps emissive lengths are $254 \mathrm{~nm}$ and $365 \mathrm{~nm}$ respectively.

\subsection{Photodegradation procedures- Analysis}

The reservoir is filled with 3 liters of a distilled water solution containing phenol and $\mathrm{TiO}_{2}$ catalyst. The experiments were investigated by varying the power of irradiation, $\mathrm{TiO}_{2}$ concentration mixture, $\mathrm{pH}$ and phenol initial concentration.

The experiments of adsorption onto $\mathrm{TiO}_{2}$ were conducted in a helical Pyrex reactor, having a capacity of $0.5 \mathrm{I}$. The suspensions were set in circulation during 2 hours in the absence of light in order to reach equilibrium adsorption before irradiation with UV light during 6 hours in presence of oxygen obtained from the air. The samples of reaction suspension $(2 \mathrm{ml})$ were taken with a syringe at pre-determined time intervals and filtered using $0.45 \mathrm{~nm}$ Millipore membranes. The sample solutions were analyzed with a UV/Vis spectrophotometer (Perkin Elmer Lambda 25 UV/VIS), the phenol concentration was measured by the absorbance at $270 \mathrm{~nm}$. All the experiments were performed by continuously bubbling air through the liquid phase in order to cover the catalyst surface with oxygen and keep it constant during the oxidation process.

$\mathrm{TiO}_{2}$ photocatalyst employed was Degussa P25 with a specific surface area of $50 \mathrm{~m}^{2} \mathrm{~g}^{-1}$. The experimental studies were carried out by varying concentrations of phenol within a range of $2.5-25 \mathrm{mg} \mathrm{l}^{-1}$, concentrations of $\mathrm{TiO}_{2}$ within a range of $0.1-1{\mathrm{~g} . \mathrm{I}^{-1}}^{-1}$, suspension flows from 0.07 to $0.23 \mathrm{I} \mathrm{min}^{-1}$ due to some geometric considerations. The $15 \mathrm{~W}$ and $400 \mathrm{~W}$ low-pressure mercury vapor quartz lamps were employed as light sources to conduct UV-Visible light experiments.

The reaction temperature was kept at $32.0 \pm 0.5^{\circ} \mathrm{C}$ using a cooling system placed between the light source and the reactor. The $\mathrm{pH}$ of the reaction suspension was not adjusted (called $\mathrm{pH}_{\text {free }}=6.7 \sim 7.2$ ), except for the study of the effect of $\mathrm{pH}$. The suspended catalyst in the aqueous system was oxygenated continuously by the ambient air.

\subsection{Kinetic studies}

The Langmuir-Hinshelwood kinetic model is used to describe the mineralization process kinetics and to assume automatically that reactions take place at the surface of the catalyst particle, without any corroborating independent evidence to support this.

The Langmuir-Hinshelwood (L-H) model was initially developed to quantitatively describe gaseous-solid reactions (Satterfield, 1970). This model was recently employed to describe solid-liquid reactions (Ollis, 1985). In this model, the rate of reaction $(r)$ is proportional to the fraction of surface covered by the substrate $(\theta)$

$\mathrm{r}=-\mathrm{dC} / \mathrm{dt}=\mathrm{k}_{\mathrm{r}} \theta$

Considering Langmuir's equation

$$
\begin{aligned}
& \theta=\mathrm{KC} /(1+\mathrm{KC}) \\
& \mathrm{r}=-\mathrm{dC} / \mathrm{dt}=\mathrm{k} \theta=\mathrm{k}_{\mathrm{r}} \mathrm{KC} /(1+\mathrm{KC})
\end{aligned}
$$






Figure 2. Experimental setup of the helical photocatalytic reactor

Since $\mathrm{k}_{\mathrm{r}}$ is the true rate constant, which takes into account several parameters (Fernández et al., 1995) such as the catalyst's mass, efficient photon flow, $\mathrm{O}_{2}$ layer, etc., $\mathrm{K}$ is the constant of adsorption equilibrium of L-H or the Langmuir constant. In photocatalytic studies, the value of $\mathrm{K}$ is obtained empirically through a kinetic study in the presence of light, and is better than that obtained in the darkness (Pedro et al., 2006), starting from Langmuir's isotherm. C is the concentration of the organic substrate at any time t. This equation can be integrated, becoming:

$\ln \left(\mathrm{C}_{0} / \mathrm{C}\right)+\mathrm{K}\left(\mathrm{C}_{0}-\mathrm{C}\right)=\mathrm{k}_{\mathrm{r}} \mathrm{Kt}$

where $\mathrm{C}_{0}$ is the initial concentration of the organic substrate and $t$ is the irradiation time. eq. (3) will be of zero order when the concentration $C(\mathrm{~mol} / \mathrm{l})$ is relatively high, $>5 \times 10^{-3}$ (Herrmann, 1999), KC $>>1$, in which case the reaction rate will be maximal. When the solution is highly diluted, $\mathrm{C}(\mathrm{mol} / \mathrm{l})<10^{-3}$ (Herrmann, 1999), the term KC becomes $<<1$, when the denominator of eq. 3 is neglected and the reaction is essentially an apparent first order reaction:

$\mathrm{r}=-\mathrm{dC} / \mathrm{dt}=\mathrm{k}_{\mathrm{r}} \mathrm{kC}=\mathrm{k}_{\mathrm{app}} \mathrm{C}$

where $k_{a p p}$ is the apparent rate constant of a pseudo first order reaction. Thus, eq. 4 can be simplified to a first order reaction when Co is very small, in which case one has:

$\ln \left(\mathrm{C}_{0} / \mathrm{C}\right)=\mathrm{k}_{\mathrm{app}} \times \mathrm{t}$

By plotting $\ln \left(\mathrm{C}_{0} / \mathrm{C}\right)$ versus $\mathrm{t}$, the apparent rate constant $\left(\mathrm{k}_{\mathrm{app}}\right)$ can be determined from the slope of the curve obtained.

\section{RESULTS AND DISCUSSION}

Several parameters have been studied in order to determine their influence on the degradation of phenol by the photochemical process $\mathrm{O}_{2} / \mathrm{UV} / \mathrm{TiO}_{2}$. We will mention the withdrawal point for sample analysis (reservoir and outflow), the irradiation light, the pollutant 
and the amount of catalyst, the $\mathrm{pH}$ of the solution, and the recirculation flow of the solution. The effect of these parameters on the photocatalytic reaction of phenol elimination has been studied by measuring the phenol concentrations over time and comparing kinetic constants. It has been observed that during the adsorption period (2 hours) the amount of phenol adsorbed was limited. The photodegradation of phenol using $\mathrm{TiO}_{2}$ as a catalyst could be modeled assuming a pseudo-first-order kinetics.

The photodegradation efficiency for each experiment also called conversion is calculated by the following relation:

$$
X(\%)=100 \times\left(C_{0}-C\right) / C_{0}
$$

Where $X$ is the photodegradation efficiency, Co the concentration of phenol before illumination and $C$ the concentration of phenol in suspension after time $t\left(\mathrm{mmol}^{-1}\right)$.

\subsection{Influence of sample point}

In order to study the influence of the sample point on the experiments, we used two different sources: one at the outflow of the reactor and the other from the reservoir. As shown in Figure 3 , the photodegradation of phenol was very important and quick for a $400 \mathrm{~W}$ light, and for both the reservoir and the outflow of the reactor, the points of the two curves are close together. This means that the choice of sample point doesn't have any effect on the phenol conversion rate. It is due to a good homogenization of the solution by the recirculation pump. Furthermore, the volume exposed to UV light is weak in relation to the total volume of solution in reservoir.

\subsection{Effect of flowrate recirculation}

Adsorption and photodegradation of phenol was carried out with varying flowrates $(0.07$ to $\left.0.231 \mathrm{~min}^{-1}\right)$. According to Figure 4 and 5 which represent the evolution of phenol degradation

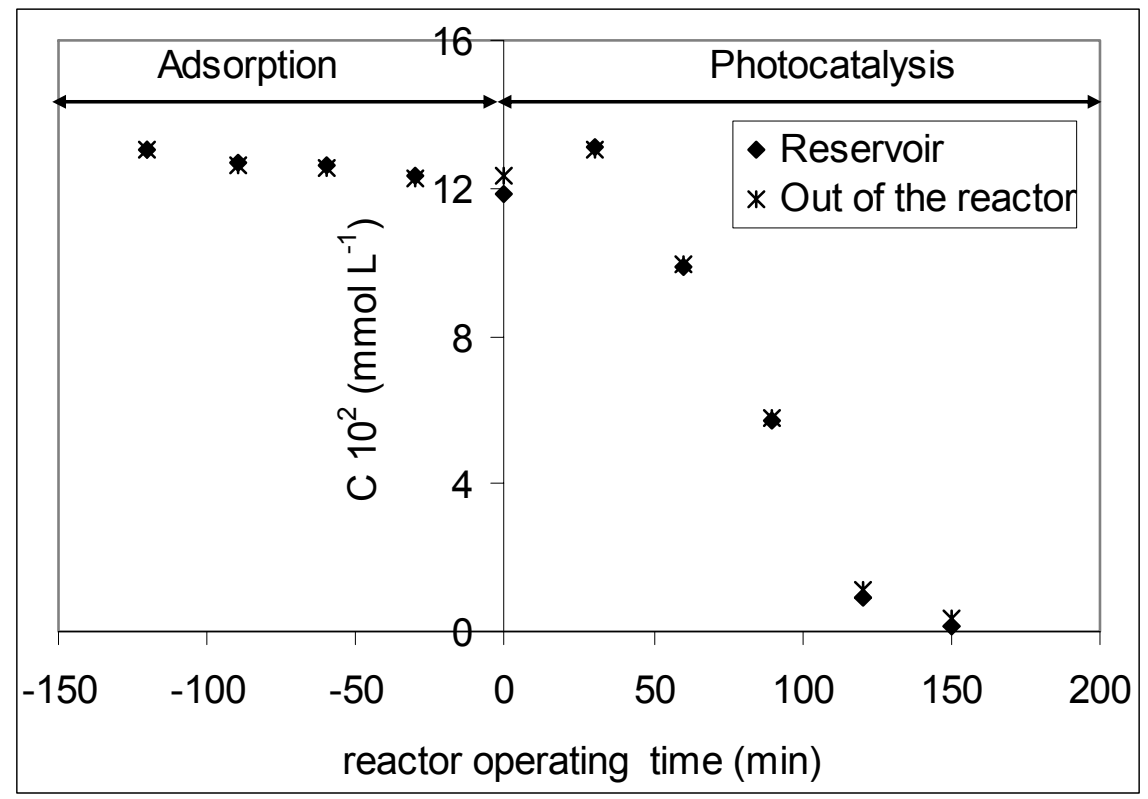

Figure 3. Effect of sample point on phenol degradation

$\left(\mathrm{C}_{0}(\right.$ phenol $\left.)=10 \mathrm{mg} \mathrm{l}^{-1}, \mathrm{C}_{\mathrm{TiO}_{2}}=1 \mathrm{~g} \mathrm{I}^{-1}, \mathrm{Q}=0.23 \mathrm{I} \mathrm{min}^{-1}, \mathrm{~T}=32^{\circ} \mathrm{C}, \mathrm{P}=400 \mathrm{~W}\right)$

while using $15 \mathrm{~W}$ and $400 \mathrm{~W}$ lights respectively, the photocatalytic activity of $\mathrm{TiO}_{2}$ and the reduction of phenol concentration with reaction time was more effectiveness with a $400 \mathrm{~W}$ light and a weaker flow (Okamoto et al., 1985), indeed, it appeared that the conversion of the phenol was very weak ( $2 \%$ for $15 \mathrm{~W}$ light), compared with $99.8 \%$ for the $400 \mathrm{~W}$ light, where phenol nearly disappeared completely (Blake, 1997). 


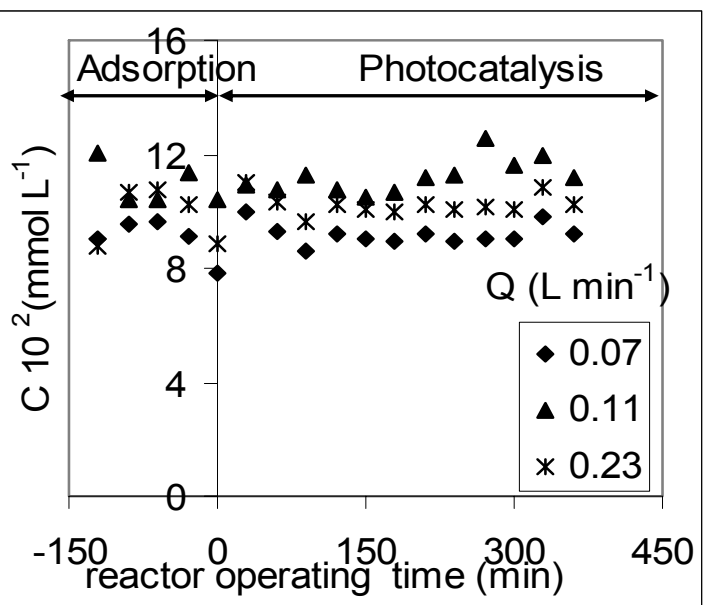

Figure 4. Evolution of phenol concentration with reactor operating time using a $15 \mathrm{~W}$ lamp. $\left(\mathrm{C}_{0 \text { (phenol) }}=10 \mathrm{mg} \mathrm{I}^{-1}, \mathrm{C}_{\mathrm{TiO} 2}=1 \mathrm{~g} \mathrm{I}^{-1}\right.$, $\mathrm{T}=32^{\circ} \mathrm{C}, \mathrm{pH}$ free)

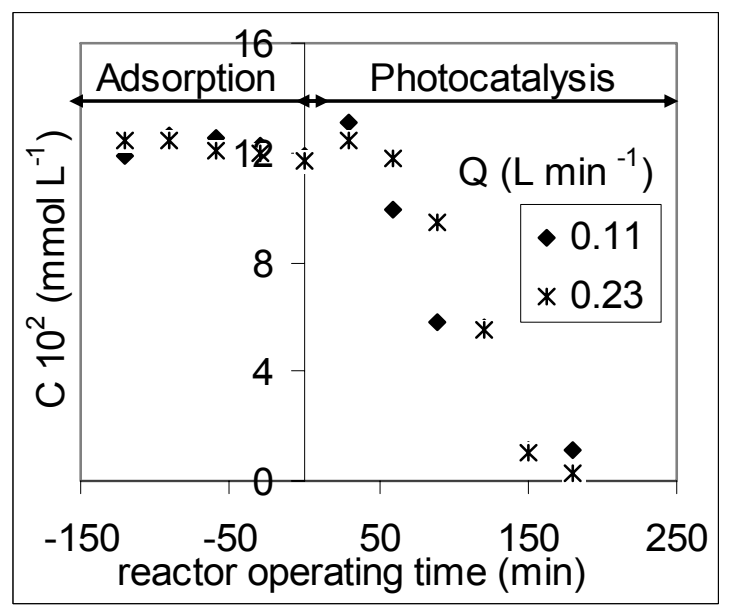

Figure 5. Evolution of phenol concentration with reactor operating time using a $400 \mathrm{~W}$ lamp. $\quad\left(\mathrm{C}_{\mathrm{o} \text { (phenol) }}=10 \mathrm{mg} \mathrm{l}^{-1}, \mathrm{C}_{\mathrm{TiO} 2}=1 \mathrm{~g} \mathrm{l}^{-1}\right.$, $\mathrm{T}=32^{\circ} \mathrm{C}, \mathrm{pH}$ free)

By plotting $-\ln (-d C / d t)$ versus $-\ln (C)$, which gives a straight line for the studied samples, the apparent rate constants $\left(k_{\text {app }}\right)$ have been determined from the slope of the curves obtained by the least squares method. Table 1 summarizes the values of $Q, X$ and the pseudo first-order rate constant $\left(k_{\mathrm{app}}\right)$ for the $400 \mathrm{~W}$ light source where the degradation of phenol was more effective. As shown in table 1 , even if $k_{\text {app }}$ is slightly better for a flowrate of $0.11 \mathrm{I} \mathrm{min}^{-1}$, we chose as the limit flowrate $Q=0.23 \mathrm{I} \mathrm{min}^{-1}$ in order to avoid the deposit of catalyst on the photoreacteur and to get a better output.

Table 1. Kinetic constants for different flowrates while using the HPA 400W lamp after 6 hours of irradiation time

\begin{tabular}{cccc}
\hline Parameter & Units & \multicolumn{2}{c}{ Values } \\
\hline Flowrate Q & $\mathrm{I} \mathrm{min}^{-1}$ & 0.11 & 0.23 \\
\hline Conversion X & $\%$ & 97.3 & 99.8 \\
\hline $\mathrm{k}_{\text {app }}$ & $\mathrm{min}^{-1}$ & $2.34 \pm 0.02$ & $1.70 \pm 0.02$ \\
\hline
\end{tabular}

\subsection{Effect of light intensity}

The incident light intensity is expected to be one of the rate-controlling parameters. In order to illustrate this effect, experiments were carried out under two levels of incident light intensity, and the conversion rate at different times is represented in Figure 6 . The mineralization processes at 15 and $400 \mathrm{~W}$ of light intensity are also displayed in Figure 6.

Based on Figure 6, the conversion depended strongly on the incident light intensity, thus, increasing the light intensity from $15 \mathrm{~W}$ to $400 \mathrm{~W}$ enhanced phenol degradation in a remarkable way, since at $400 \mathrm{~W}$, conversion reached $100 \%$ after less than 4 hours, whereas the conversion at $18 \mathrm{~W}$ led to less than $15 \%$ even after a long irradiation time.

These results may be explained based on the relative amounts of photons in the reaction system at low light intensity; on the other hand, at high intensity, photons were present in excessive amounts leading to more reactive species generation and more destruction of phenol; this proved that higher catalyst activity occurred under high light incident intensity.

\subsection{Effect of the dose of semiconductor $\left(\mathrm{TiO}_{2}\right)$}

The effect of the amount of $\mathrm{TiO}_{2}$ Degussa P25 on the removal of phenol was also significant as shown in Figure 7, confirming the positive influence of the increased number of $\mathrm{TiO}_{2}$ active sites on the process kinetics. Figure 7 displays phenol concentrations in the suspension for various catalyst dosages (interval $0.1-1.0 \mathrm{~g} \mathrm{I}^{-1}$ ). These results show that the photocatalytic efficiency for phenol degradation increased with the increase of the amount of $\mathrm{TiO}_{2}$. This observation can be explained by the photocatalyst optical properties as the main cause for 
the differences, indeed, the total active surface area increased with increasing catalyst dosage, because of the penetration of UV light into the suspension which in turn increases the number of hydroxyl, and superoxide radicals.

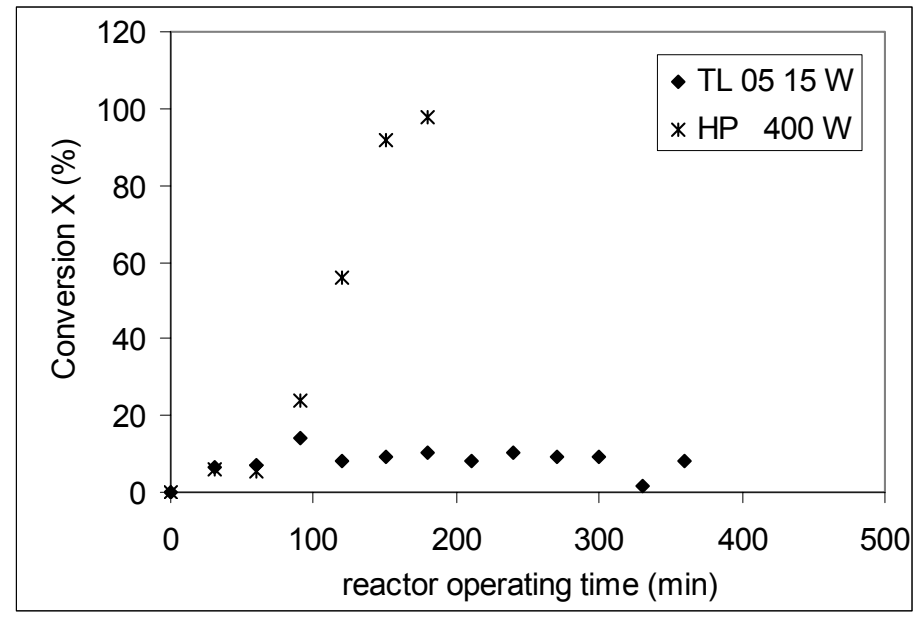

Figure 6. Effect of UV light on conversion with reactor operating time for two different light intensities. $\left(\mathrm{C}_{0}(\right.$ phénol $\left.)=10 \mathrm{mg} \mathrm{l}^{-1}, \mathrm{C}_{\mathrm{TiO} 2}=1 \mathrm{~g} \mathrm{~L}^{-1}, \mathrm{Q}=0.23 \mathrm{I} \mathrm{min}^{-1},=32^{\circ} \mathrm{C}\right)$

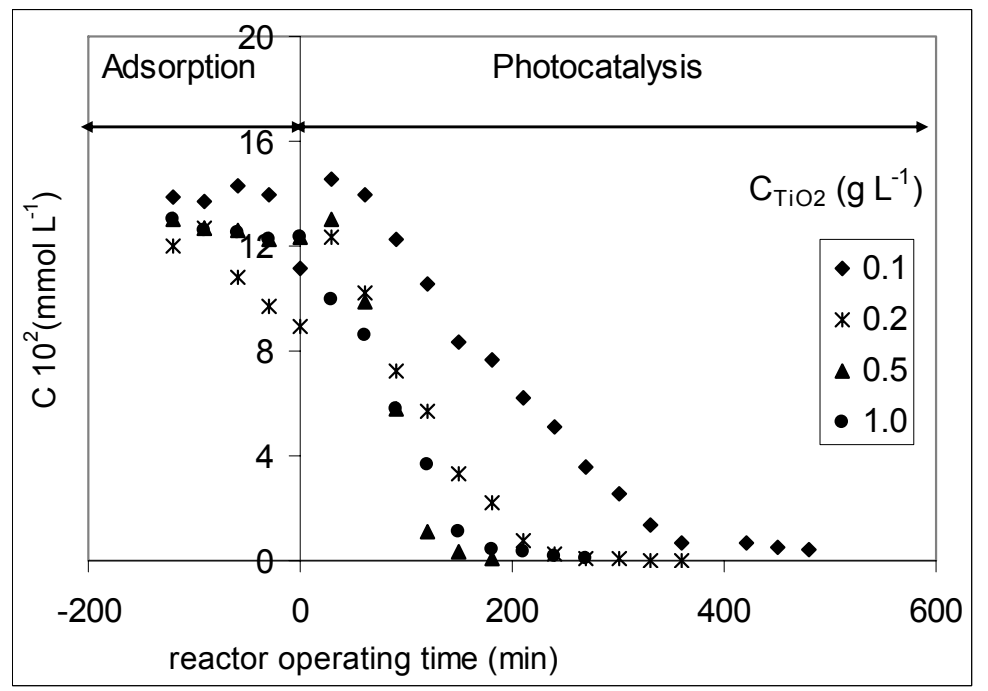

Figure 7. Effect of titanium dioxide concentration on phenol degradation

$\left(\mathrm{C}_{0}(\right.$ phenol $)=10 \mathrm{mg} \mathrm{l}^{-1}, \mathrm{Q}=0.23 \mathrm{I} \mathrm{min}^{-1}, \mathrm{~T}=32^{\circ} \mathrm{C}, \mathrm{pH}$ free, $\left.\mathrm{P}=400 \mathrm{~W}\right)$.

As shown in table 2, the phenol degradation was achieved after 4 hours for the major chosen concentration $(X=99 \%)$. However, as shown in Figure 8, over the whole range of $\mathrm{TiO}_{2}$ loading values $\left(0.2\right.$ to $\left.1.0 \mathrm{~g} \mathrm{l}^{-1}\right)$, there were no significant changes, so the other experiments were performed in the $\mathrm{TiO}_{2}$ concentration of $0.2 \mathrm{~g} \mathrm{l}^{-1}$ (Hermann, 1999).

Table 2. Decomposition of phenol solutions at different initial $\mathrm{TiO}_{2}$ concentrations

\begin{tabular}{cccccc}
\hline Parameter & Units & \multicolumn{5}{c}{ Values } \\
\hline Amount of $\mathrm{TiO}_{2}$ & $\mathrm{~g}^{-1}$ & 0.1 & 0.2 & 0.5 & 1.0 \\
\hline Period of reaction & hour & 6.0 & 4.0 & 4.5 & 3.0 \\
\hline Conversion X & $\%$ & 94.00 & 99.00 & 97.55 & 99.15 \\
\hline $\mathrm{k}_{\text {app }}$ & $\mathrm{min}^{-1}$ & $0.37 \pm 0.03$ & $0.78 \pm 0.01$ & $1.40 \pm 0.02$ & $1.77 \pm 0.01$ \\
\hline
\end{tabular}


In this study, in the dynamic flow photoreactor, apparent first-order reaction rate constants were found to be directly proportional to the concentration of catalyst (Figure 8). This indicates a true heterogeneous catalytic regime.

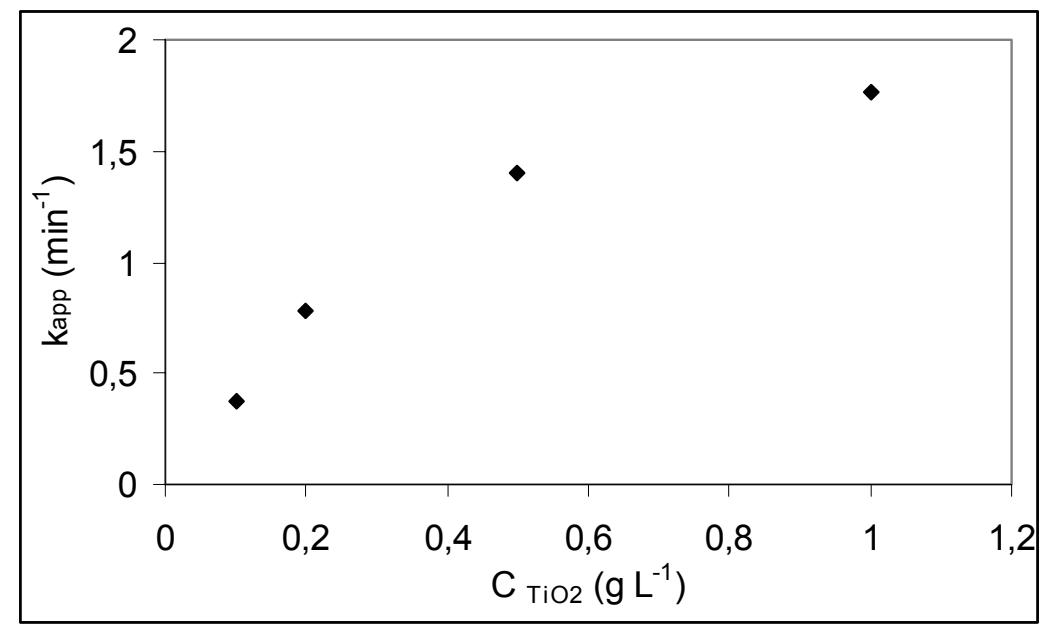

Figure 8. Apparent first-order constant rate vs. initial concentration of $\mathrm{TiO}_{2}$ $\left(\mathrm{C}_{0}\right.$ (phenol) $=10 \mathrm{mg} \mathrm{l}^{-1}, \mathrm{Q}=0.23 \mathrm{I} \mathrm{min}^{-1}, \mathrm{~T}=32^{\circ} \mathrm{C}, \mathrm{pH}$ free, $\mathrm{P}=400 \mathrm{~W}$ )

However, above a certain value of $\mathrm{C}_{\mathrm{TiO} 2}$, the reaction rate became constant and independent of $\mathrm{C}_{\mathrm{TiO2}}$. These limits correspond to the maximum amount of $\mathrm{TiO}_{2}$ in which all the particles and the entire surface exposed were totally illuminated. To be sure that we had total absorption of efficient photons and to avoid excess catalyst in our recirculation plug flow reactor, we have chosen an optimum $\mathrm{C}_{\mathrm{TiO} 2}$ concentration of $0.2 \mathrm{~g}^{-1}$, as suggested by Hermann, (1999) and as shown in table 2, where it was indicated that $99 \%$ of phenol has been degraded after 4 hours.

\subsection{Effect of $\mathrm{pH}$ on the degradation of phenol}

The effect of $\mathrm{pH}$ on the photocatalytic degradation efficiency of AOPs, according to some literatures (Wang et al., 2000), is one of the major factors influencing the rate of degradation of some organic compounds (Pera-Titus et al., 2004). The degradation of phenol under UV irradiation at different $\mathrm{pH}$ is shown in Figure 10; Figure 9 shows that the suspension $\mathrm{pH}$ (without any adjustment) changed with time, during the adsorption period, no change was observed, so the influence of adsorption can be neglected. Initially, the solution was colorless, but immediately after the irradiation, the suspension $\mathrm{pH}$ decreased, and a pink coloration appeared. After a few minutes the color changed to vivacious red, after a few more minutes, the color began to disappear and the solution finally became colorless.

The increase of the $\mathrm{pH}$ from 7.2 to 6.7 was noticed from the beginning and this latter $\mathrm{pH}$ remained constant during the whole run, thus acid compounds were produced. The acids seem to be the most difficult compounds to be mineralized (Mantzavinos et al., 1996), likewise, for the formed intermediates reaction products, such as aromatics (hydroquinone, benzoquinone and catechol), which result from reaction of hydroxyl radicals with phenol, at the initial stage of the reaction and undergo further photocaltalytic oxidation to yield the very polar products like aldehydes and carboxylic acids which increased rapidly. The aromatic intermediates disappeared some minutes after the disappearance of phenol. After reaching a maximum, acids decreased with increasing reaction time and at the end of the degradation phenol was mineralized to $\mathrm{CO}_{2}$ and $\mathrm{H}_{2} \mathrm{O}$ (Okamoto et al., 1985). As shown in Figure 10 and table 3 , Phenol conversions were found to 


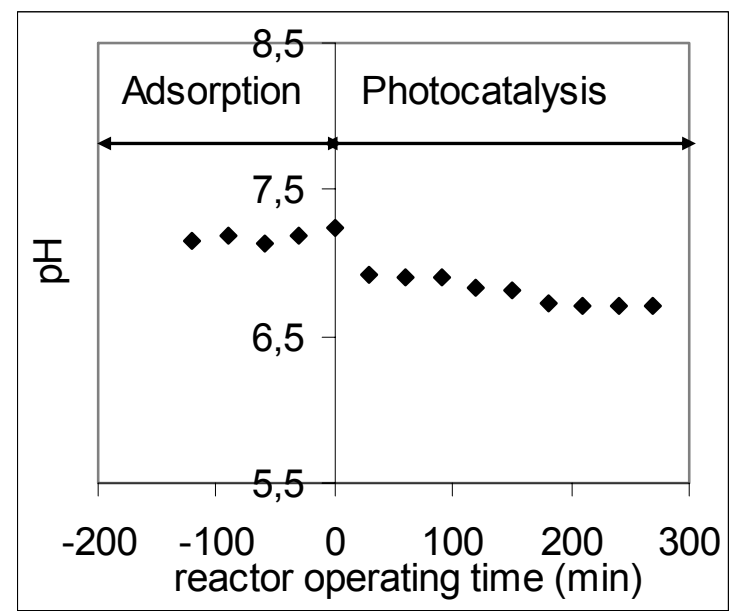

Figure 9. Effect of $\mathrm{pH}$ on the photocatalytic degradation of phenol with an irradiation of $400 \mathrm{~W} .\left(\mathrm{C}_{\mathrm{o}}\right.$ (phenol) $=10 \mathrm{mg} \mathrm{l}^{-1}, \mathrm{C}_{\mathrm{TiO} 2}=0.2 \mathrm{~g} \mathrm{I}^{-1}$, $\mathrm{Q}=0.23\left(\mathrm{~min}^{-1}, \mathrm{~T}=32^{\circ} \mathrm{C}\right)$

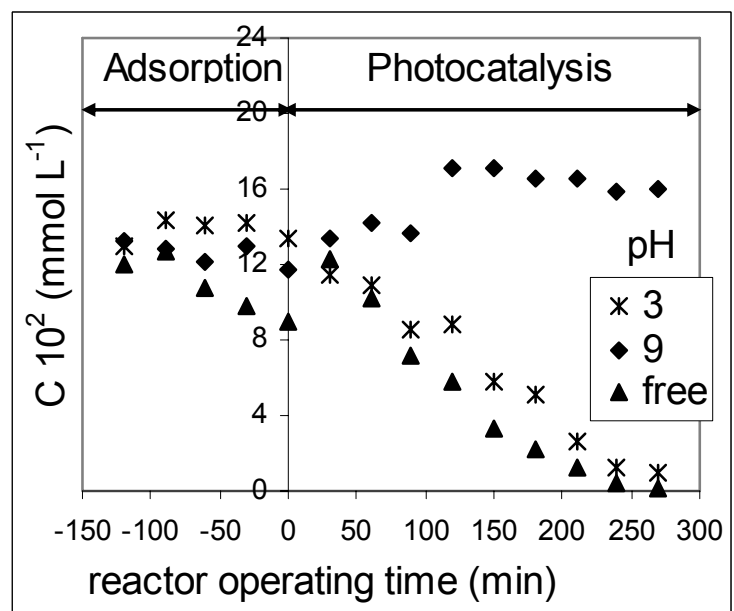

Figure 10. Effect of $\mathrm{pH}$ on photocatalytic degradation of phenol with an irradiation of $400 \mathrm{~W} .\left(\mathrm{C}_{\mathrm{o}}\right.$ (phenol) $=10 \mathrm{mg} \mathrm{I}^{1}, \mathrm{C}_{\mathrm{TiO} 2}=0.2 \mathrm{~g} \mathrm{I}^{-1}$, $\mathrm{Q}=0.23 \mathrm{I} \mathrm{min}^{-1}, \mathrm{~T}=32^{\circ} \mathrm{C}$, )

be more important for acid than for basic media, Okamoto et al., (1985) and Serpone et al., (1996) have reported that $\mathrm{pH} 3$ was the optimum for the photocatalytic decomposition of phenol. The photodegradation of phenol was complete after 5 hours. On the other hand, the $\mathrm{pH}$ value obtained at the end of the experiment was similar to the initial $\mathrm{pH}$ solution; this indicated that mineral acids and carbon dioxide would be considered as the final oxidation products. Whereas in $\mathrm{pH} 9$, conversion reached a threshold value of about $46 \%$, indeed,

higher $\mathrm{pH}$ retarded the formation of $\mathrm{HO}^{\bullet}$ radicals and decreased the photocatalytic reaction rate. Besides, $\mathrm{TiO}_{2}$ coagulates at $\mathrm{pH} 9$ and the samples of the reaction slurry could not be filtrated and analyzed (Leyva et al. 1998) the residual phenol indicates a moderate degradation, Table 3 shows that the order of reaction rates was $\mathrm{pH}_{\text {free }}(6.7-7.2)>\mathrm{pH} 3>\mathrm{pH} 9$. This means that it was more effective for phenol to be degraded under natural conditions.

Table 3. $\mathrm{K}_{\mathrm{app}}$ rate constants and conversions at different $\mathrm{pH}$ values with a HPA 400W lamp

\begin{tabular}{ccccc}
\hline Parameter & Units & \multicolumn{3}{c}{ Values } \\
\hline $\mathrm{pH}$ & -- & 3 & $\begin{array}{c}\text { free } \mathrm{pH} \\
(6.7-7.2)\end{array}$ & 9 \\
\hline Conversion X & $\%$ & 96.51 & 98.96 & 46.59 \\
\hline $\mathrm{k}_{\text {app }}$ & $\mathrm{min}^{-1}$ & $\begin{array}{c}1.032 \pm \\
0.007\end{array}$ & $1.34 \pm 0.01$ & $0.450 \pm 0.008$ \\
\hline
\end{tabular}

Table 3 shows that the better removal efficiency of phenol is in low pH values, and the optimal $\mathrm{pH}$ for the studied system is the free one, this is due to the process of the photocatalytic degradation of phenol, which involves not only radical oxidation, but also direct electron transfer and surface sorption reactions. Notice also the lower values of the pseudo-first order kinetic constant obtained when runs were carried out at basic $\mathrm{pH}$.

\subsection{Effect of the initial concentration of Phenol}

The effect of the initial phenol concentration on its kinetic degradation by the UV/TiO $/ \mathrm{O}_{2}$ process was investigated. Figure 11 and Table 4 show that between 56 and $99 \%$ of the phenol content was removed by the AOP for initial phenol concentrations ranging from 2.5 to $25 \mathrm{mg} \mathrm{l}^{-1}$, at free $\mathrm{pH}$ and illumination light of 400W. As shown in Figure 11, the fact that a negligible adsorption took place indicates that the phenol was not physically adsorbed but chemically reacted on the catalyst surface (Santos et al., 1999). 


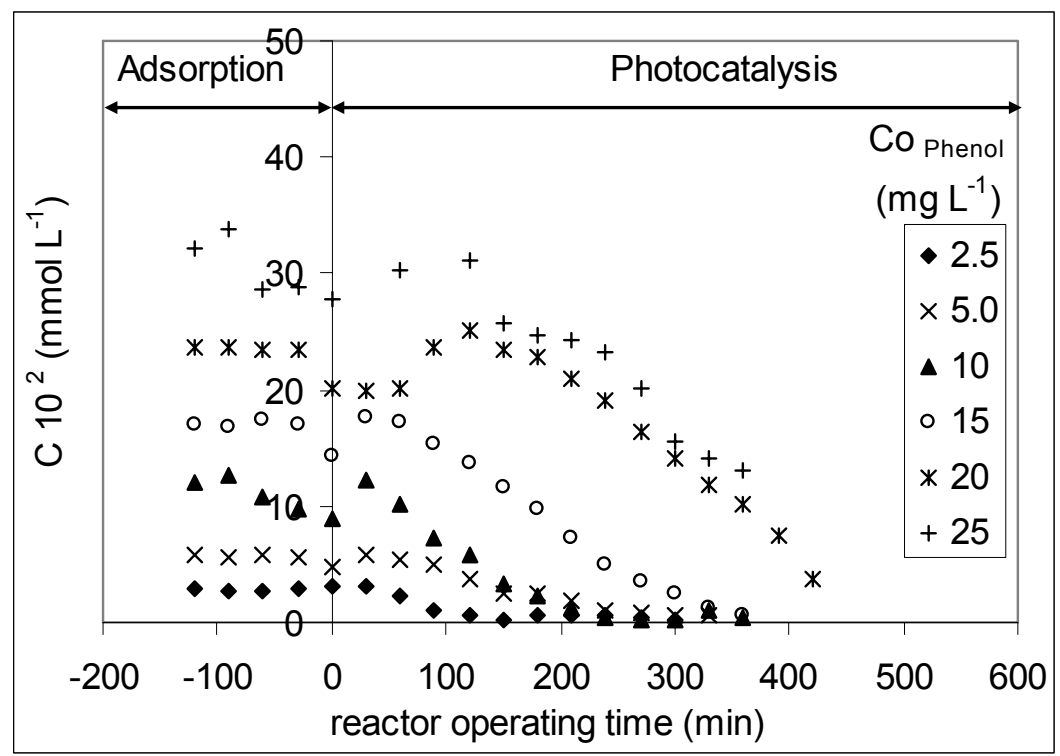

Figure 11. Effect of initial concentration of phenol on the Photocatalytic degradation under UV light illumination

$$
\left(C_{\mathrm{TiO}_{2}}=0.2 \mathrm{~g} \mathrm{I}^{-1}, \mathrm{Q}=0.23 \mathrm{I} \mathrm{min}^{-1}, \mathrm{~T}=32^{\circ} \mathrm{C}, \mathrm{pH} \text { free, } \mathrm{P}=400 \mathrm{~W}\right) \text {. }
$$

Afterwards, the time required for complete degradation of phenol solutions increased with increasing initial phenol concentration. On the other hand, an optimal value was obtained for $\mathrm{C}_{0}=2.5 \mathrm{mg} \mathrm{l}^{-1}$, where a high degradation efficiency of phenol (about $99 \%$ ) was attained with an irradiation time less than $2 \mathrm{~h}$. This is not the case for other concentrations where the required time to obtain this performance was much longer. An explanation at this behavior is that as initial concentration increases, a bigger quantity of phenol is adsorbed on the surface of $\mathrm{TiO}_{2}$, therefore, the generation of hydroxyl radicals would be reduced since there were fewer active sites for the adsorption of hydroxyl ions and the generation of hydroxyl radicals. Further, as the concentration of phenol in solution increased, the photons would be able to be intercepted before they could reach the catalyst surface, hence the absorption of photons by the catalyst decreased, and consequently the degradation was reduced.

Table 4. Apparent first-order rate constants and conversions for different initial concentrations of phenol. $\left(C_{\mathrm{TiO} 2}=0.2 \mathrm{~g} \mathrm{I}^{-1}, \mathrm{Q}=0.23 \mathrm{I} \mathrm{min}^{-1}, \mathrm{~T}=32^{\circ} \mathrm{C}\right)$

\begin{tabular}{cccccccc}
\hline Parameter & Units & \multicolumn{7}{c}{ Values } \\
\hline $\mathrm{C}_{0}$ phenol & $\mathrm{mg}^{-1}$ & 2.5 & 5 & 10 & 15 & 20 & 25 \\
\hline $\mathrm{X}$ & $\%$ & 90.44 & 89.00 & 98.62 & 96.62 & 83.9 & 56.2 \\
\hline $\mathrm{k}_{\text {app }}$ & $\mathrm{min}^{-1}$ & 7.73 & 2.62 & 1.78 & 0.761 & 0.600 & 0.2300 \\
& & \pm 0.02 & \pm 0.02 & \pm 0.01 & \pm 0.009 & \pm 0.009 & \pm 0.0005 \\
\hline
\end{tabular}

It has been observed that in photocatalytic processes, formation, migration and reaction of photogenerated radicals with organic compounds were consecutive reactions, therefore, any of these processes could determine the overall degradation rate. As shown in table 4, the apparent first-order rate constants decreased with the increase of initial phenol concentrations (Matthews, 1988). This is the consequence of the Intermediates, which were generated during the photocatalytic process and affect the degradation of phenol by producing higher concentrations of intermediates adsorbed at higher initial concentrations of phenol; this could affect negatively the overall degradation rate. The competitive adsorption on the surface of $\mathrm{TiO}_{2}$ particles between the $\mathrm{HO}^{*}$ radicals generated by the active site $\mathrm{OH}^{-}$and phenol molecules adsorbed on the surface catalyst which react with radicals has the similar effect. When the initial concentration is high, the number of these available active sites are decreased by phenol, and since the intensity of irradiation light was constant the $\mathrm{HO}^{\bullet}$ and $\mathrm{O}_{2}^{-\bullet}$ radicals formed on the surface of the catalyst were also constant, the attack oft these 
radicals on the compound molecules decreased and simultaneously the photodegradation efficiency also decreases.

\subsection{Kinetic studies}

The photocatalytic oxidation kinetics of many organic compounds has often been modeled with the Langmuir-Hinshelwood equation, which also covers the adsorption properties of the substrate on the photocatalyst surface. This model, developed by Turchi et al. (1990) and Emeline et al. (2000), is expressed as eq.3, where $r$ is the reaction rate $\left(\mathrm{mmol}^{-1} \mathrm{l}^{-1} \mathrm{~min}^{-1}\right), \mathrm{k}_{\mathrm{r}}$ the reaction rate constant $\left(\mathrm{mmol} . \mathrm{I}^{-1} \mathrm{~min}^{-1}\right), \mathrm{K}$ the adsorption equilibrium constant of phenol (I $\left.\mathrm{mmol}^{-1}\right)$, and $\mathrm{C}$ the concentration of phenol $\left(\mathrm{mmol} \mathrm{l}^{-1}\right)$. The initial degradation rate of phenol was studied as a function of the initial phenol concentration in the range 2.5 to $25 \mathrm{mg} \mathrm{l}^{-1}$, for a fixed loading of $\mathrm{TiO}_{2}\left(0.2 \mathrm{~g} \mathrm{I}^{-1}\right)$. The results were reported in Figure 11. The initial phenol degradation rate versus initial phenol concentration under photocatalytic conditions showed at high initial concentration a plateau, the approximate value was $[\text { phenol }]_{0}=30 \times 10^{-2} \mathrm{mmol} \mathrm{I}^{-1}$. Eq.8 shows a pseudo-first order reaction with respect to the phenol concentration.

The relationship between the initial degradation rate $(r)$ and the initial concentration of organic substrate for a heterogeneous photocatalytic degradation process has been described by Langmuir-Hinshelwood model and can be written as follows:

if we consider that the kinetic of phenol degradation is of pseudo-order, at $\mathrm{t}=0$ and $\mathrm{C}=\mathrm{C}_{0}$, eq. 3 becomes:

$\mathrm{r}_{0}=\mathrm{k}_{\mathrm{r}} \mathrm{KC}_{0} /\left(1+\mathrm{KC}_{0}\right)$

This equation can be rearranged into linear form:

$1 / r_{0}=\left(1 / k_{r} K\right) \cdot 1 / C_{0}+1 / k_{r}$

where $1 / r_{0}$ is the dependent variable, $1 / C_{0}$ the independent variable, $1 / k_{r}$ is the linear coefficient and $\left(1 / \mathrm{k}_{\mathrm{r}} \mathrm{K}\right)$ the angular coefficient of the straight line (Figure 13). From this model, the $\mathrm{L}-\mathrm{H}$ adsorption constant and the rate constant were obtained by plotting $1 / \mathrm{r}_{0}$ versus $1 / \mathrm{C}_{0}$ (Wang et al., 2000).

The values of the adsorption equilibrium constant, $\mathrm{K}$, and the kinetic rate constant of surface reaction, $k_{r}$, were calculated. The representation of $1 / r_{0}$ versus $1 / C_{0}$, as shown in equ. 9 in the presence of different concentrations of phenol versus initial phenol concentration yields a straight line indicating a pseudo-first order reaction. The reaction rate constants $k_{r}$ for photocatalytic degradation of phenol were evaluated from experimental data (Figure 13) using a linear regression. The $\mathrm{R}^{2}$ (correlation coefficient) value was higher than 0.99 , which

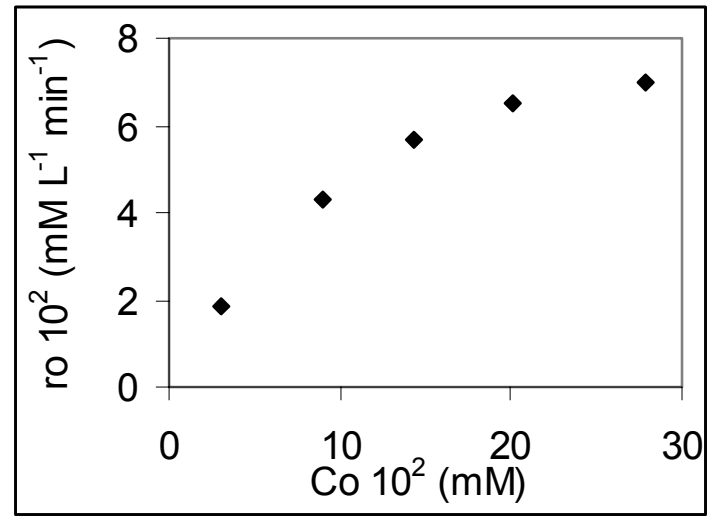

Figure 12. Initial phenol degradation rate vs. initial phenol concentration. $\left(C_{\mathrm{TiO} 2}=0.2 \mathrm{~g} \mathrm{I}^{-1}, \mathrm{Q}=0.23 \mathrm{I} \mathrm{min}^{-1}, \mathrm{~T}=32^{\circ} \mathrm{C}\right)$.

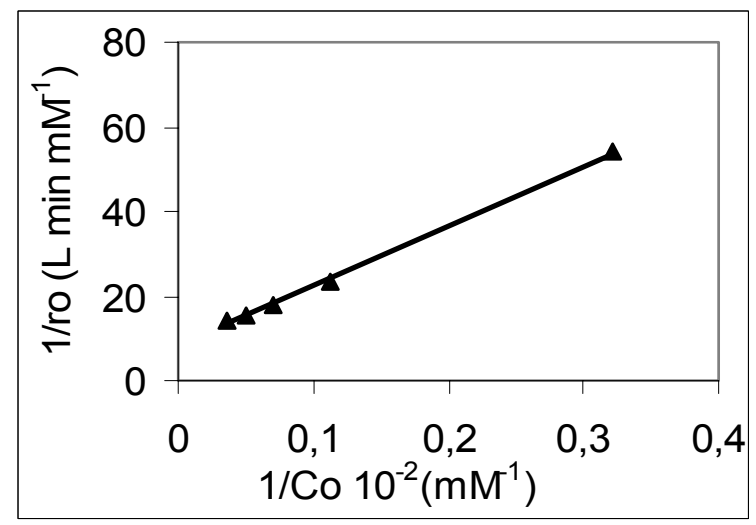

Figure 13. Linearization of LangmuirHinshelwood's equation for phenol. $\left(C_{\mathrm{TiO} 2}=0.2 \mathrm{~g} \mathrm{I}^{-1}, \mathrm{Q}=0.23 \mathrm{I} \mathrm{min}^{-1}, \mathrm{~T}=32^{\circ} \mathrm{C}\right)$

confirms the proposed kinetics for degradation of phenol in this process. The constants $\mathrm{k}_{\mathrm{r}}$ and $\mathrm{K}$ in Langmuir-Hinshelwood model were obtained as $0.1204 \mathrm{mmol}^{-1} \mathrm{I}^{-1} \mathrm{~min}^{-1}$ for $\mathrm{k}_{\mathrm{r}}$ and 0.0604 $\mathrm{I} \mathrm{mmol}^{-1}$ for $\mathrm{K}$, with correlation coefficient $\mathrm{R}^{2}$ equal to 0.995 . 


\section{CONCLUSION}

The performance of the helical reactor conceived in our laboratory for the heterogeneous photocatalysis of phenol in suspension were studied. This reactor appears to be a promising technology to degrade phenol and many other environmentally persistent compounds. This process proved to be a very efficient method for water pollution remediation as a complete mineralization of phenol. The photodegradation of phenol in presence of $\mathrm{TiO}_{2}$ suspension was found to be the best method for its degradation. Several parameters have been studied, it appears that the flowrate recirculation, irradiation time, light intensity, catalyst load, $\mathrm{pH}$ and concentration of phenol mainly controls the rate of degradation for which optimum conditions for achieving maximum efficiency were established. Taking into account the role of the different parameters should be of great importance for the optimization of the experimental conditions for technological applications.

In this work, it appears that the degree of degradation of phenol was obviously affected by illumination time, recirculation flowrate, light intensity, amount of photocatalyst, suspension $\mathrm{pH}$ and initial concentration. A weak recirculation flowrate, high light intensity, moderate catalytic concentration, free $\mathrm{pH}$ of the suspension with a value of 6.7-7.2, and a weak initial concentration of phenol promoted the photodegradation of phenol. Indeed, the capacity of $\mathrm{TiO}_{2}$ towards phenol degradation strongly depended on the suspension $\mathrm{pH}$. At basic $\mathrm{pH}$, degradation was negligible, and at acid or free $\mathrm{pH}$, degradation of phenol was fast indicating that the mechanism involving complete mineralization could be achievable under prolonged exposures. At the optimal conditions, $99 \%$ of phenol was degraded after approximately 4 hours. Under the operational conditions employed, the phenol oxidation reaction could take place by the free radicals mechanism, the catalyst being an initiator of such reactions. However, the total mineralization of the intermediates is affected by the catalyst concentration, especially when the reaction takes place under basic conditions. The kinetics of photocatalytic removal of phenol followed the Langmuir-Hinshelwood model, with apparent first-order kinetic.

\section{REFERENCES}

Al-Hayek N. and Dore M., (1990), Oxidation of phenols in water by hydrogen peroxide on alumine supported iron, Water Research, 24, 973-982.

Andreozzi R., Caprio V., Insola A. and Marotta R., (1999), Advanced oxidation process (AOP) for water purification and recovery, Catal. Today, 53, 51-59.

Azbar N. and Kestigliu Yonar K., (2004), Comparison of various advanced oxidation processes and chemical treatment methods for COD and color removal from a polyester and acetate fiber dyeing effluent, Chemosphere, 55, 35-43.

Blake D.M., (1997), Bibliography of Work on photocatalytic removal of hazardous compounds from water and air, NREL/TP-430-22197, National Renewable Energy Laboratory, Golden.

Bremner D.H., Burgess A.E., Houllemare D. and Namkung K.C., (2006), Phenol degradation by using hydroxyl radicals generated from zero-valence iron and hydrogen peroxide, Applied Catalysis B: Environmental, 63, 15-19.

Brezová V., Ceppan M., Brandstetova E., Breza M. and Lapcik L., (1991), Photocatalytic hydroxylation of benzoic acid in aqueous titanium dioxide suspension, J. Photochemistry and Photobiology A: Chemistry, 59, 385-391.

Chiron S., Fernandez-Alba A., Rodriguez A. and Garcia-Calvo E., (2000), Pesticide chemical oxidation: State of the art., Water Research, 34, 366-377.

Datye A.K., Riegel G., Bolton J.R., Huang M., Prairie M.R., (1995), Microstructural characterization of a fumed titanium dioxide photocatalyst, J. Solid State Chem. ,115, 236-239.

Emeline A.V., Salinaro A., Ryabchuk V.K. and Serpone N., (2001), Photo-induced processes in heterogeneous nanosystems from photoexcitation to interfacial chemical transformations, Int. J. Photoenergy, 3, 1-16.

Emeline A.V., Ryabchuk V. and Serpone N., (2000), Factors affecting the efficiency of a photocatalysed process in aqueous metal-oxide dispersions, Prospect of distinguishing between two kinetic models, Journal of Photochemistry and Photobiology A: Chemistry, 133, 89-97.

Esplugas S., Yue P.L. and Perez M.I., (1994), Degradation of 4-chlorophenol by photolytic oxidation, Water Research, 28, 1323-1328. 
Fernández A., Lassaletta G., Jiménez V.M., Justo A., González-Elipe A.R., Jerrmann J.M., Tahiri $\mathrm{H}$. and Ait-lchou Y., (1995), Preparation and characterization of $\mathrm{TiO}_{2}$ photocatalysts supported on various rigid supports (glass, quartz and stainless steel). Comparative studies of photocatalytic activity in water purification, Applied Catalysis B: Environmental, 7, 49-63.

Fox M.A., Dulay M.T., (1993), Heterogeneous photocatalysis, Chem. Rev. 93, 341-357.

Glaze W.H., Peyton G.R., Lin S., Hhuang F.Y. and Burleson J.L. (1982), Destruction of pollutants in water with ozone in combination with ultraviolet radiation, Environ. Sci. Technol., 16, 454-461.

Galze H., Beltran F., Tuhkanen T. and Kang J.W., (1992), Chemical models of advanced oxidation processes, Water Poll. Res. J. Canada, 27, 23-42.

Guélou J., Barrault J., Fournier J. and Tatibouët J.-M., (2003), Active iron species in the catalytic wet peroxide oxidation of phenol over pillared clays containing iron Applied catalysis $B$ : Environmental, 44, 1-8.

Hagfeldt A. and Gratzel M., (1995), Light-induced redox reactions in nanocrystalline systems, Chem. Rev. 95, 49-68.

Herrmann J.M., (1999), Heterogeneous photocatalysis: fundamentals and applications to the removal of various types of aqueous pollutants, Catalysis Today, 53, 115-129.

Hoffmann M.R., Martin S.T., Choi W. and Bahnemann D.W., (1995), Environmental applications of semiconductor photocatalysis, Chem. Rev., 95, 69-96.

Horikoshi S., Watanabe N., Mukae M., Hidaka H. and Serpone N., (2001), Mechanistic examination of titania-photocatalyzed oxidation of ethanolamines, New J. Chem., 25, 9991005.

Huang C.P., Dong C. and Tang Z., (1993) Advanced chemical oxidation: its present role and potential future in hazardous waste treatment, Waste Management, 13, 361-377.

Kavan L., Gratzel M., Gilbert S., Klemenz C. and Scheel H.J., (1996), Electrochemical and photoelectrochemical investigation of single-crystal anatase, J. Am. Chem. Soc. 118, 6716-6723.

Legrini O., Oliveros E. and Braun A.M., (1993) Photochemical processes for water treatment, Chem. Rev., 93, 671-698.

Leyva E., Moctezuma E., Ruíz M.G. and Torres-Martínez L., (1998), Photodegradation of phenol and 4-chlorophenol by $\mathrm{BaO}-\mathrm{Li}_{2} \mathrm{O}-\mathrm{TiO}_{2}$ catalysts, Catalysis Today, 40, 367-376.

Mantzavinos D., Hellenbrand R., Livingston A.G. and Metcalfe I.S., (1996), Catalytic wet oxidation of p-coumaric acid: Partial oxidation intermediates, reaction pathways and catalyst leaching, Appl. Catal. B: Environmental, 7, 379-396.

Matthews R.W., (1990), Purification of water with near-u.v. illuminated suspensions of titanium dioxide, Water Research, 24, 653-660.

Matthews R.W., (1988), Kinetics of photocatalytic oxidation of organic solutes over titanium dioxide, J. Catal., 111, 264-272.

Mirat D.G. and Vatistas R., (1997), Oxidation of phenolic compounds by ozone and ozone-UV radiation: a comparative study, Water Research, 21, 895-900.

Mokrini A., Ousse D. and Esplugas S., (1997), Oxidation of aromatic compounds with UV radiation/ozone/hydrogen peroxide, Water Sci. Technol., 35, 95-102.

Ohno T., Jarukawa K., Tokieda K., Matsumura M., (2001), Morphology of a $\mathrm{TiO}_{2}$ Photocatalyst (Degussa, P-25) consisting of anatase and rutile crystalline phases, J.Catal., 203, 82-86.

Okamoto K.I., Yamamoto Y., Tanaka H., Tanaka M. and Itaya A., (1985), Heterogeneous photocatalytic decomposition of phenol over $\mathrm{TiO}_{2}$ powder, Bull. Chem. Soc. Jpn., 58, 2015-2022.

Ollis D.F., (1985), Contaminant degradation in water: heterogeneous photocatalysis degrades halogenated hydrocarbon contaminants, Environmental Science and Technology, 19, 480484.

Pedro J.S., Valente S., Padilha P.M. and Florentino A.O., (2006), Studies in the adsorption and kinetics of photodegradation of a model compound for heterogeneous photocatalysis onto $\mathrm{TiO}_{2}$, Chemosphere, 64, 1128-1133.

Pellizzetti E., Macrino V., Minero C., Carlin V., Pramauro E., Zerbinati O. and Tosano M.L., (1990), Photocatalytic degradation of atrazine and other s-triazine herbicides, Environ. Sci. Technol., 24, 1559-1565. 
Pera-Titus M., Garcia-Molina V., Baños M.A., Giménez J. and Esplugas S., (2004), Degradation if chlorophenols by means of advanced oxidation processes: a general review, Applied Catalysis B: Environmental, 47, 219-256.

Safarzadeh-Amiri A., Bolton J.R. and Caster S.R., (1996), The use of iron in advanced oxidation processes, J. Adv. Oxid. Technol., 1, 18-26.

Salinaro A., Emeline A., Zhao J., Hidaka H., Ryabchuk V.K. and Serpone N., (1999), Terminology, relative photonic efficiencies and quantum yields in heterogeneous photocatalysis. Part II: Experimental determination of quantum yields, Pure Appl. Chem., 71, 321-335.

Santos A., Barroso E. and García-Ochoa F., (1999), Overall rate of aqueous-phase catalytic oxidation of phenol: $\mathrm{pH}$ and catalyst loading influences, Catalysis Today, 48, 109-117.

Satterfield, C.N., (1970), Mass Transfer in Heterogeneous Catalysis. MIT Press, Cambridge, MA, $177-179$.

Serpone N., (1996), in Kirk-Othmer Encyclopedia of Technology, Wiley-Interscience, New York, 18, 820.

Tang H., Berger H., Schmid P.E. and Lévy F., (1994), Optical properties of anatase $\left(\mathrm{TiO}_{2}\right)$, Solid State Commun., 92, 267-271.

Tennakone K., Tilakaratne C.T.K. and Kottegoda I.R.M., (1997). Photomineralization of carbofuran by $\mathrm{TiO}_{2}$-supported catalyst, Water Research, 31, 1909-1912.

Turchi C.S. and Ollis D.F., (1990), Photocatalytic degradation of organic water contaminants: mechanisms involving hydroxyl radical attack, J. Catal., 122, 178-192.

Wang K.H., Hisieh Y.H., Wu C.H. and Chang C.Y. (2000), The pH and anion effects on the heterogeneous photocatalytic degradation of o-methylbenzoic acid in $\mathrm{TiO}_{2}$ aqueous suspension, Chemosphere, 40, 389-394.

Weir B.A. and Sundstrom D.W., (1993), Destruction of trichloroethylene by UV light catalysed oxidation with hydrogen peroxide, Chemosphere, 27, 1279-1291. 